Check for updates

Cite this: RSC Adv., 2018, 8, 41237

\title{
The low-temperature corrosion characteristics of alcohol-based fuel combustion
}

\author{
Zhiqiang Wang, Xuge Lu, (D) Xingxing Cheng (D) and Chunyuan Ma
}

In this paper, the low-temperature corrosion characteristics of the four fuel combustions that include methanol, diesel, MF75 (the volume fraction of methanol is $75 \pm 2 \%$ ), and MF50 (the volume fraction of methanol is $50 \pm 2 \%$ ) were studied. MF75 and MF50 were modulated by methanol, diesel and a small amount of cosolvent. The quality indicators of four fuels were judged by the specific standard. The acid dew point temperature of the four kinds of fuel combustion flue gas was calculated and compared, and the acid ion in the condensate of the four fuel combustion products was analyzed and tested. Based on this method, the corrosiveness of four kinds of condensate was determined. The corrosion rates of five metals (brass, 304 stainless steel, 316 stainless steel, corten steel, and Q245 steel) were tested by two different methods (electrochemistry corrosion and static immersion corrosion). The experimental results show that the quality indicators of four fuels have all reached the relevant national standards. The dew point temperature of methanol, MF75 and MF50 are lower than that of diesel. The corrosion products on the surface of corten steel are relatively compact and easily accumulate dust, which is not conducive to the safe operation of the boiler. The corrosion resistance properties of 316 stainless steel is excellent, showing that it would be the ideal material choice for the low-temperature zone of a boiler flue.

Received 4th July 2018

Accepted 3rd December 2018

DOI: $10.1039 / \mathrm{c} 8 \mathrm{ra} 05705 \mathrm{~b}$

rsc.li/rsc-advances the boiler, which causes corrosion to the components in the area. Biomass fuel contains a high content of chlorine and potassium, and the alkali metal chloride produced after combustion deposits on the heating surface of the boiler causing corrosion. At present, researchers are working on developing various forms of new fuel. Alcohol-based fuel is gradually being valued and promoted due to its low sulfur content and low emissions. ${ }^{4-7}$

With the development of research in alcohol-based fuels, alcohol-based fuels are increasingly being used in the industrial boiler industry. Compared with fossil fuels, the combustion of alcohol-based fuels can greatly reduce the emission of flue gas pollutants. ${ }^{8,9}$ So it is quite important to study the corrosion of metals in the combustion of alcohol-based fuels. Methanol has active chemical properties and strong polarity, and has a certain degree of corrosion to metals. The existence of an acid dew point in fuel combustion fumes is the key to low temperature corrosion. Owing to various factors, the temperature of the acid dew point is in dynamic change. The critical temperature of sulfuric acid mist generated by $\mathrm{SO}_{3}$ and water vapor in the flue gas is named the flue gas acid dew point. The $\mathrm{SO}_{2}$ and $\mathrm{SO}_{3}$ in the flue gas from the combustion of sulfur-containing fuel, combined with steam could generate $\mathrm{H}_{2} \mathrm{SO}_{3}$ vapor and $\mathrm{H}_{2} \mathrm{SO}_{4}$ vapor, which increases the dew point temperature of the actual flue gas compared with the dew point temperature of pure water vapor. ${ }^{10}$ The $\mathrm{H}_{2} \mathrm{SO}_{4}$ vapor condenses at the low-temperature heating surface of the boiler will result in corrosion, when the
National Engineering Laboratory for Coal-fired Pollutants Emission Reduction, Shandong University, 17923 Jingshi Road, Jinan 250061, PR China. E-mail: xcheng@sdu.edu.cn 
Table 1 Technical parameters of the boiler

\begin{tabular}{llcc}
\hline Kind & Model & Rated evaporation & $\begin{array}{l}\text { Rated steam } \\
\text { temperature }\end{array}$ \\
\hline Horizontal type steam boiler & WNS1-0.7-170-Y & $1 \mathrm{t} \mathrm{h}^{-1}$ & $170{ }^{\circ} \mathrm{C}$
\end{tabular}

Table 2 Technical parameters of the burner

\begin{tabular}{|c|c|c|c|c|}
\hline Kind & Model & Power supply & $\begin{array}{l}\text { Rated combustion } \\
\text { power }\end{array}$ & $\begin{array}{l}\text { Rated fuel } \\
\text { consumption }\end{array}$ \\
\hline Burner & JH-CA-0.7MW & $4 \mathrm{~kW}$ & $0.7 \mathrm{MW}$ & $90 \mathrm{~kg}$ \\
\hline
\end{tabular}

temperature of the low-temperature heating surface of the boiler is lower than the dew-point temperature of the flue gas. It is easy to cause low temperature corrosion of the boiler's tail that use waste heat to reduce the temperature of the exhaust fumes. ${ }^{11-14}$ The small amount of chlorine ions in the fuel can affect the boiler superheater tube corrosion in various ways, and resulting in accelerated oxidation and corrosion of the flue metal after combustion. The presence of alkali metal chloride salts in sediments may also lead to accelerated corrosion. ${ }^{15-18}$ $\mathrm{SO}_{4}{ }^{2-}$ and $\mathrm{NO}_{3}{ }^{-}$in condensate produced by combustion of $\mathrm{S}$ element and $\mathrm{N}$ elements in fuel also cause corrosion. Therefore, it is great significance to study the acid dew point temperature of alcohol-based fuels to prevent the occurrence of lowtemperature corrosion and the corrosion characteristics of the condensate to the metal.

In this paper, the acid dew point temperature of the four kinds of fuel combustion flue gas was calculated and compared, and the quality indicators of four fuels were judged based on the national standard. The acid ion in the condensate of the four fuels was analyzed to judge its corrosion characteristics. The corrosion rate of metal in a specific medium is the main parameter for evaluating the corrosion resistance of metal. In order to provided a theoretical basis for the low-temperature corrosion of metal by condensate of four kinds of fuel combustion products.

\section{Experiment}

\subsection{Acid dew point experiment tests}

2.1.1 Experimental materials. Fuels: methanol, diesel oil, MF75, MF50. Instrument: KM9106 flue gas analyzer. See Tables 1 and 2 for the boiler technical parameters and the burner parameters.

2.1.2 Experimental method. Table 3 shows the elemental of the fuels, and according to the following formula, the acid dew

Table 3 The elemental of the fuels $/ \%$

\begin{tabular}{lllll}
\hline Fuels & Methanol & MF75 & MF50 & Diesel oil \\
$\mathrm{S}_{\mathrm{ar}}$ & 0 & 0.048 & 0.095 & 0.190 \\
Ash & 0.0020 & 0.0014 & 0.0011 & 0.00099
\end{tabular}

point was calculated. ${ }^{19-22}$

$$
t_{\mathrm{ld}}=t_{\mathrm{sl}}+\frac{\beta \times \sqrt[3]{\mathrm{S}_{\mathrm{ar}, z \mathrm{~s}}}}{1.05^{\alpha_{\mathrm{fh}} \mathrm{A}_{\mathrm{ar}, 2 \mathrm{~s}}}}
$$

where, $t_{\mathrm{ld}}-\mathrm{ADT}\left({ }^{\circ} \mathrm{C}\right) ; t_{\mathrm{sl}}$ - steam dew point temperature of pure water under the same partial pressure $\left({ }^{\circ} \mathrm{C}\right) ; \mathrm{S}_{\mathrm{ar}, \mathrm{zs}}$-converted sulfur; $\mathrm{A}_{\mathrm{ar}, \mathrm{zs}}$-converted ash; $\alpha_{\mathrm{fh}}$-fly ash coefficient; $\beta$ empirical coefficient.

$$
t_{\mathrm{sl}}=-1.2102+8.4064 \varphi_{\mathrm{H}_{2} 0}-0.4749 \varphi_{\mathrm{H}_{2} 0}{ }^{2}+0.01042 \varphi_{\mathrm{H}_{2} 0}{ }^{3}
$$

where, $\varphi_{\mathrm{H}_{2} \mathrm{O}}-$ moisture content.

\subsection{Electrochemical tests}

2.2.1 Experimental solution and metal specimens preparation. The experimental solution: four kinds of fuel combustion condensate. The experimental metal materials: brass, 304 stainless steel, 316 stainless steel, Q245 steel, and corten Steel.

Electrochemical tests metal specimens preparation: the size of metal specimens for electrochemical test was $1 \mathrm{~cm} \times 1 \mathrm{~cm}$, the back sides of the specimens were filled with epoxy resin and special silica gel sealant, only one face was exposed to the electrolyte. The specimens surface was ground via SiC paper progressively to 2000 grit, respectively. After that, the specimens were cleaned with distilled water and absolute ethanol solution, then dried by cool air. ${ }^{23}$

2.2.2 Experimental method. A CS350 electrochemical workstation was selected to perform the electrochemical corrosion behaviour. Using a three-electrode system which include a working electrode, an auxiliary electrode, and a reference electrode. A platinum foil was used as auxiliary electrodes and a saturated calomel electrode (SCE) was used as reference electrodes. Five kinds of metal specimens were used as a working electrodes, respectively. Before the electrochemical test, work electrodes were initially immersed in the electrolyte for a while to approach the steady state. ${ }^{23}$ According to the corrosion potential, the point-scanning range of the steady-state polarization curve was determined. Then the polarization curves of the working electrode in different electrolyte was obtained, respectively and the corrosion rate was calculated using 
Table 4 Acid dew point temperature of the four kinds of fuel $/{ }^{\circ} \mathrm{C}$

\begin{tabular}{lllll}
\hline Fuels & Methanol & MF75 & MF50 & Diesel oil \\
ADT & 55.4 & 73.3 & 76.3 & 81.3
\end{tabular}

the analysis software of the CS350 electrochemical workstation. $^{24}$

\subsection{Static immersion corrosion test}

The experimental mediums: methanol, diesel, MF75, MF50 and four kinds of fuel combustion condensate. The experimental metal materials: brass, 304 stainless steel, 316 stainless steel, Q245 steel, and corten Steel.

Static immersion corrosion test metal specimens preparation: the size of metal specimens for static immersion corrosion test was $1 \mathrm{~cm} \times 1 \mathrm{~cm}$, the back sides of the metal specimens were embedded in epoxy resin and special silica gel sealant, only one face was exposed to the solution. The specimens surface was ground via SiC paper sequentially to 1000 grit, respectively. After that, the specimens were cleaned with distilled water and absolute ethanol solution, than put it in a drying oven to dry it. The metal specimens was weighed by the electronic balance as the initial weight of the corrosion reaction.

The corrosion rate was calculated using the following equation:

$$
V=\left(W_{1}-W_{0}\right) / S t
$$

where, $V$-corrosion rate, $\mathrm{mg}\left(\mathrm{cm}^{-2} \mathrm{~h}^{-1}\right) ; W_{0}$-sample before corrosion quality, mg; $W_{1}$-sample after corrosion quality, mg; $S$-surface area of test piece, $\mathrm{cm}^{2} ; t$-corrosion time, h.

MF75 and MF50 were modulated by methanol and diesel with a small amount of cosolvent. Oxygen can convert sulfur compounds of diesel fuel to trace element sulfur, which is highly corrosive to non-ferrous metals. ${ }^{25}$ Copper corrosion is an important quality indicator to judge oil products. The quality indicators of four fuels were judged based on the national standard "GB/T 5096-2017 Test method for corrosiveness to copper from petroleum products by copper strip test".

The experimental method of the national standard: take $30 \mathrm{~mL}$ sample of completely clear, non-suspended water into a clean, dry test tube. The copper piece was slid into the test tube and immersed in the sample within 1 minute after the completion of the final polishing step of the copper sheet. The test tube is clogged with a cork with a vent, and each tube was immersed in a bath at $50{ }^{\circ} \mathrm{C} \pm 1{ }^{\circ} \mathrm{C}$. During the experiment, strong light should be prevented from illuminating the contents of the test tube. The test tube was placed in the bath for $3 \mathrm{~h} \pm$ $5 \mathrm{~min}$ and removed. After placing in the bath for $3 \mathrm{~h} \pm 5 \mathrm{~min}$, remove the test tube and copper sheet, and immerse the copper sheet in the washing solvent to wash away the sample. After cleaning, the copper was taken out from the washing solvent immediately, and blotted dry with filter paper. The copper sheet is compared to a corrosion-standard colorimetric plate to check for discoloration or corrosion and to determine the corrosion level of the copper sheet.

\section{Results and discussion}

\subsection{Acid dew point temperature}

Table 4 shows the acid dew point temperature of the four kinds of fuel. It can be concluded that the acid dew point temperature of methanol, MF75 and MF50 is lower than that of diesel oil, and methanol has the lowest acid dew point temperature. The main composition of flue gas of the methanol combustion is $\mathrm{CO}_{2}$ and $\mathrm{H}_{2} \mathrm{O}$, the acid dew point temperature is close to the dew point temperature of the water vapor under this operating condition. Owing to the sulfur content in diesel oil, different proportion of diesel oil in fuel have a main certain effect on acid dew point. In the combustion process, sulfur is oxidized to sulfur dioxide, oxygen is decomposed to oxygen atoms, and sulfur dioxide combines with free oxygen atoms to form sulfur trioxide. The formation of sulfur trioxide is the condition of low temperature corrosion. High acid dew point makes corrosive gases more easily condense in low temperature areas, causing low temperature corrosion. ${ }^{26}$ The reaction formula of low temperature corrosion is as follows:

$$
\begin{gathered}
\mathrm{SO}_{2}+[\mathrm{O}]=\mathrm{SO}_{3} \\
\mathrm{SO}_{3}+\mathrm{H}_{2} \mathrm{O}+\mathrm{Fe} \rightarrow \mathrm{FeSO}_{4}+\mathrm{H}_{2}
\end{gathered}
$$

Compared with diesel fuel, the other three kinds of fuel can effectively recover waste heat from boiler tail, reduce exhaust loss and improve boiler thermal efficiency.

\subsection{Analysis of acid ion}

Table 5 shows the detection results of acid ion in the four kinds of condensate. The types and contents of acid ions in condensate have corrosion effects on metals. The $\mathrm{Cl}^{-}, \mathrm{SO}_{4}{ }^{2-}$ and $\mathrm{NO}_{3}{ }^{-}$

Table 5 The detection results of acid ion in the four kinds of condensate/mg L ${ }^{-1}$

\begin{tabular}{lllrl}
\hline & $\begin{array}{l}\text { Condensate of } \\
\text { methanol combustion }\end{array}$ & $\begin{array}{l}\text { Condensate of } \\
\text { MF75 combustion }\end{array}$ & $\begin{array}{l}\text { Condensate of } \\
\text { MF50 combustion }\end{array}$ & $\begin{array}{l}\text { Condensate of } \\
\text { diesel oil combustion }\end{array}$ \\
\hline $\mathrm{Cl}^{-}$ & 34.03 & 74.53 & 18.06 & 13.15 \\
$\mathrm{SO}_{4}{ }^{2-}$ & - & 27.50 & 57.55 & 263.16 \\
$\mathrm{NO}_{3}{ }^{-}$ & 0.16 & 0.07 & 0.72 & 0.54
\end{tabular}



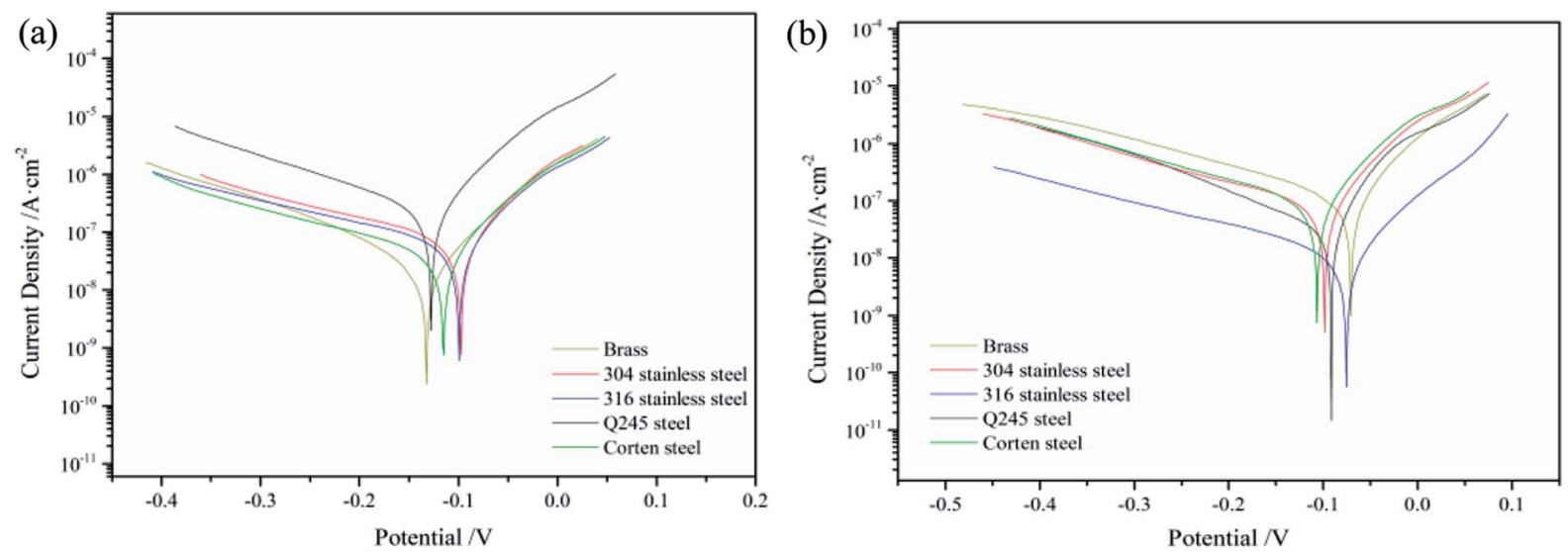

(c)

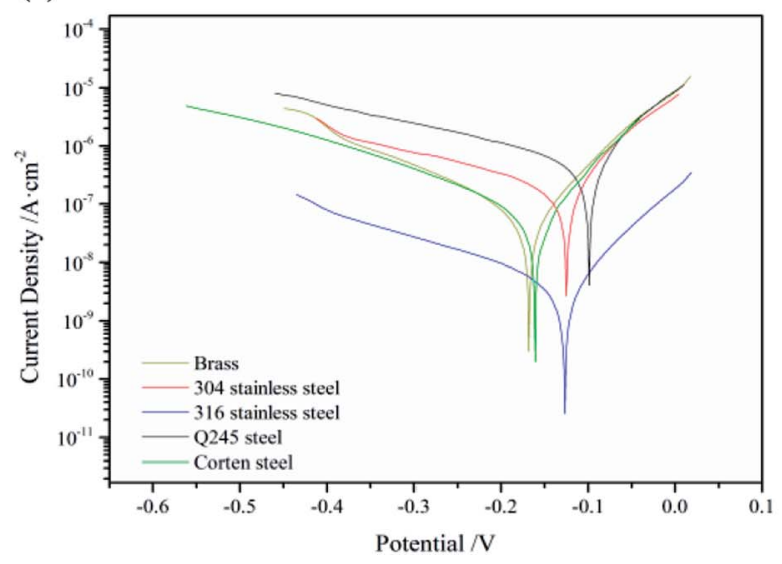

(d)

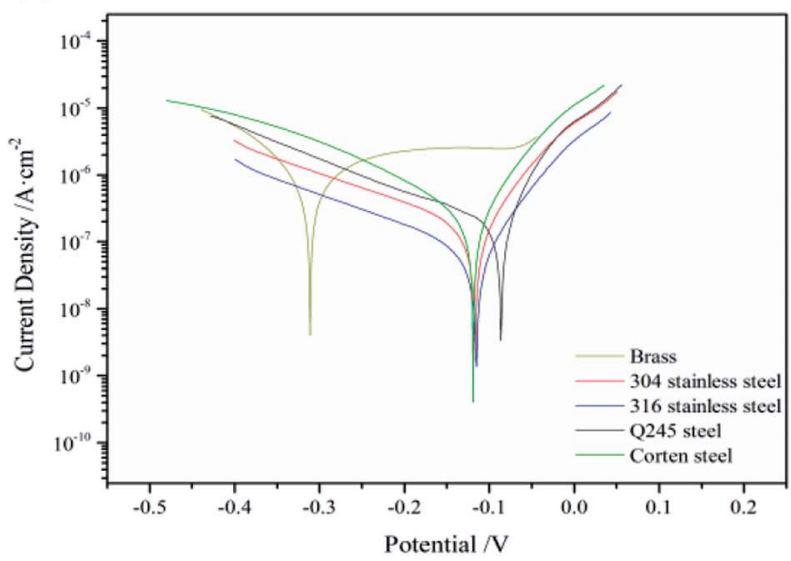

Fig. 1 Potentiodynamic polarization curves of the metal specimens in the condensate. (a) Condensate of methanol combustion, (b) condensate of diesel oil combustion, (c) condensate of MF75 combustion, (d) condensate of MF50 combustion.

of the condensate are dissolved easily in water and forming corrosive condensate. It can be concluded that the total number of the four acid ions in the condensate of diesel oil combustion is the largest. And compared with the other three kinds of fuel, the contains of sulfur is relatively high in the diesel oil which results in more $\mathrm{SO}_{4}{ }^{2-}$ in the condensate. The content of $\mathrm{SO}_{4}{ }^{2-}$ in the condensate shows an increasing trend with increasing proportion of diesel oil in fuel. The content of $\mathrm{NO}_{3}{ }^{-}$in the condensate of the four fuel combustion are relatively small. Owing to the nitrogen elements in the diesel oil and air react with oxygen at high temperatures, the content of $\mathrm{NO}_{3}{ }^{-}$in the condensate of diesel oil and MF50 combustion are relatively large, also the content of $\mathrm{NO}_{3}{ }^{-}$is related to the state of combustion. A certain amount of chlorides in methanol and diesel oil, and the content of $\mathrm{Cl}^{-}$of the condensate is high. The existence of these acid ions makes the condensate easy to generate corrosion of boiler flue at low temperature.

The adequacy of the fuel production process and the combustion process has a certain influence on the acid composition and content in the combustion condensate. The insufficiency of the fuel combustion process may result in a certain amount of formic acid in the condensate, and it could make metal corroded.

\subsection{Electrochemical analyses}

The potentiodynamic polarization results of metal specimens in condensate of different fuels combustion are shown in Fig. 1. In Fig. 2, the electrochemical corrosion rates of metal specimens in four kinds of condensate is shown and compared intuitively, as derived from the experimentally recorded cathodic and anodic polarization curves using the Tafel's linear extrapolation method. It can be seen that the four kinds of condensate have a certain influence on the electrochemical corrosion rates of metal specimens. The electrochemical corrosion rates of Q245 steel is the highest, and the electrochemical corrosion rates of 316 stainless steel is the lowest in the five kinds of metal. The corrosion resistance properties of Q245 steel is poor to condensate of four kinds of fuel combustion, and it's not suitable for equipment materials that condensate congest easily. The corrosion resistance properties of 316 stainless steel is most excellent. In the electrochemical system, the self-corrosion potential indicates the tendency of corrosion of metals, and the lower of the self-corrosion potential, the greater of the tendency of corrosion. Stainless steel has a relatively high corrosion rate due to its relatively low corrosion potential (about $-0.125 \mathrm{~V}$ ) in the MF50 combustion condensate. ${ }^{27,28}$ The chloride ion in the condensate loses electrons and generation of chlorine 


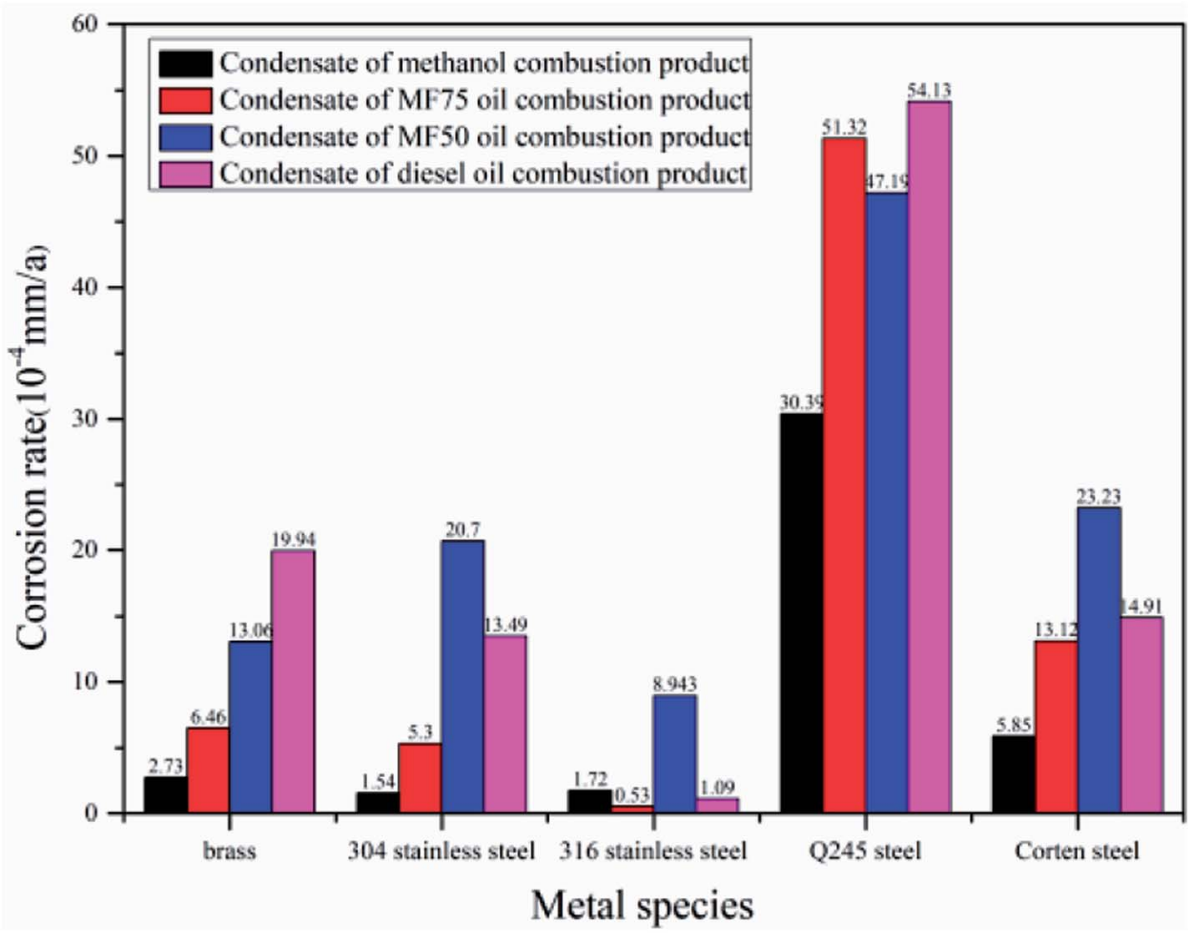

Fig. 2 The electrochemical corrosion rates of metal specimens in the condensate.

gas. And the change after the loss of electrons in the sulfate is complicated, which is unfavorable for galvanic corrosion. The content of $\mathrm{H}^{+}$in the condensate after diesel and MF50 combustion is relatively large and facilitates galvanic corrosion, so that the corrosion rate of carbon steel in the condensate of diesel and MF50 combustion is large. The electrochemical corrosion rate of brass increased with the increased of diesel oil content in the fuel. This indicates that the $\mathrm{SO}_{4}{ }^{-}$have a certain effects on electrochemical corrosion of brass, and the corrosion resistance properties of brass is poor to condensate of diesel oil combustion. Also the existence of $\mathrm{Cl}^{-}$in the condensate and the composition of brass have a certain effects on electrochemical corrosion of brass. The higher potentials under anodic polarisation when both copper and zinc dissolve, resulting the production of insoluble cuprous chloride possibility on the surface of the brass. ${ }^{29}$ The electrochemical corrosion rates of 304 stainless steel and corten steel are equivalent approximately in the condensate of MF50 and diesel oil combustion, indicating the corrosion resistance properties of them is similar in the condensate of MF50 and diesel oil combustion. The existence of $\mathrm{SO}_{4}{ }^{2-}$ and $\mathrm{Cl}^{-}$could have a certain impact to make the corrosion behaviours of stainless steel changed. ${ }^{30}$

\subsection{Analysis of static immersion corrosion test}

The corrosion mass gain of metal specimens with time in condensate of different fuels combustion are shown in Fig. 3. In Fig. 4, the static immersion corrosion rates of metal specimens in four kinds of condensate is shown and compared intuitively. It can be seen that the corrosion mass gain of 304 and 316 stainless steel is relatively slight, indicating excellent low temperature corrosion resistance. The nitrate ions and hydrogen ions in the condensate have opposite effects on the corrosion of stainless steel. The promotion of hydrogen ions and the hindrance of oxidation by nitric acid compete with each other to determine the corrosion rate of stainless steel. The ratio of hydrogen ion to nitrate ion in MF75 combustion condensate and diesel combustion condensate is relatively large, and hydrogen ion promotes the corrosion rate. The promotion of hydrogen ions is equivalent to the oxidation of nitrate ions in the MF50 combustion condensate. The oxidation of nitrate ions in the methanol combustion condensate plays a major role, so that the passivation layer on the surface of the stainless steel are able to protect the substrate and provide a good barrier. But the integrity of the oxide film which can be broken down under the synergistic effects of corrosion and erosion conditions, which result in different corrosion rate of 304 and 316 stainless steel. ${ }^{31}$ And the concentration of $\mathrm{Cl}^{-}$in condensate also has an effect on the formation of passive layer of 304 and 316 stainless steel. ${ }^{32-34}$ The corrosion mass gain of Q245 and corten steel is obvious relatively, and the static immersion corrosion rates of them is high relatively in the condensate of diesel oil combustion, indicating a poor low temperature corrosion resistance. But the corrosion resistance of corten steel is better than that of Q245 steel. The $\mathrm{SO}_{4}{ }^{2-}, \mathrm{Cl}^{-}$, and $\mathrm{H}^{+}$have a severe corrosion to the iron of Q245 steel and corten steel, and the $\mathrm{H}^{+}$ions in the condensate are the most corrosive to carbon steel. The corrosion mass gain of brass is between stainless steel and carbon steel. The static immersion corrosion rates of brass in the condensate of MF75 combustion is high relatively, and that of brass in the 

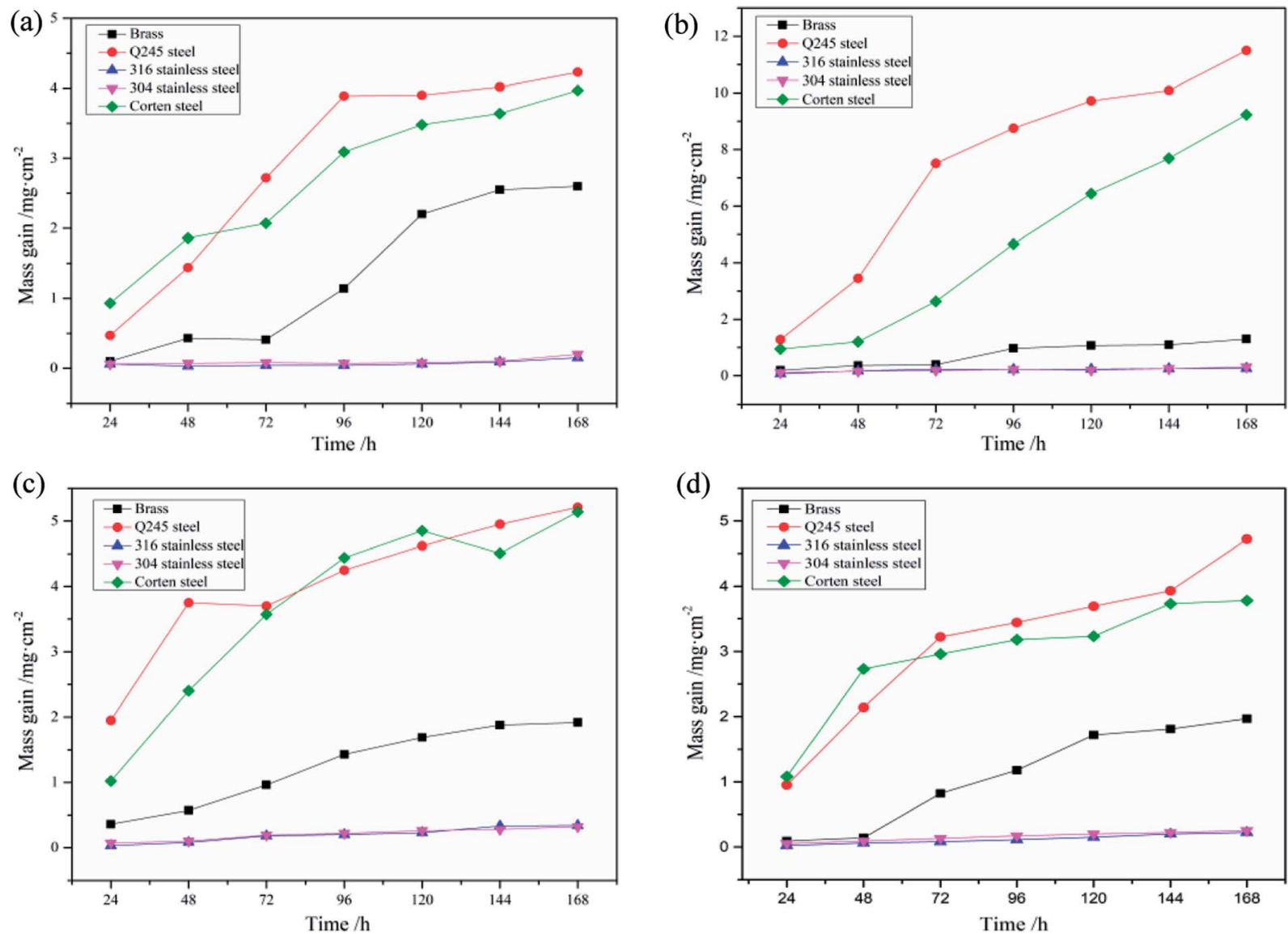

Fig. 3 The corrosion mass gain of metal specimens with time in condensate. (a) Condensate of methanol combustion, (b) condensate of diesel oil combustion, (c) condensate of MF75 combustion, (d) condensate of MF50 combustion.

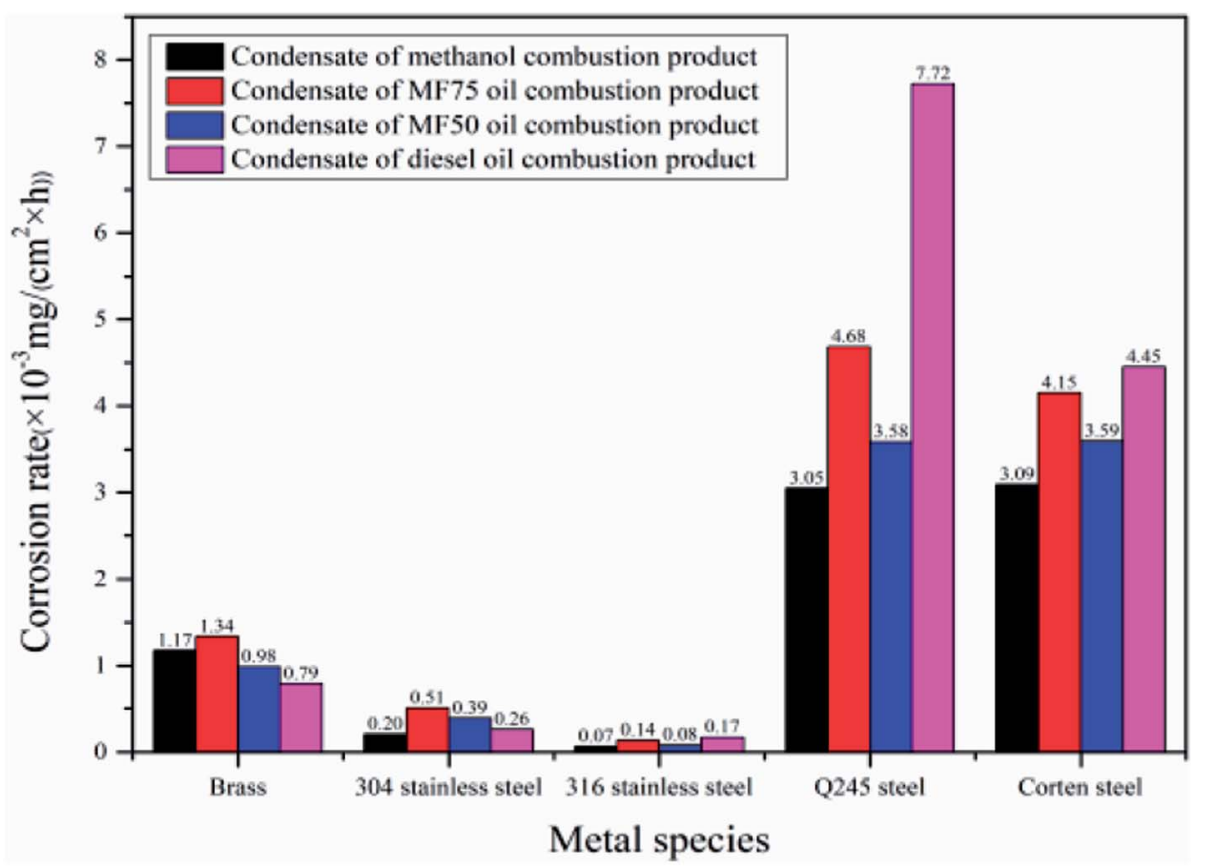

Fig. 4 The corrosion rates of metal specimens in the condensate. 
Table 6 The quality indicators of four fuels

\begin{tabular}{lllll}
\hline Fuels & Methanol & Diesel oil & MF75 & MF50 \\
Quality indicators & 1a & 1a & 1a & 1a
\end{tabular}

condensate of diesel oil combustion is slow relatively. The content of $\mathrm{Cl}^{-}$in the combustion condensate of methanol, MF75, and MF50 is higher relatively than that of diesel oil. Owing to the $\mathrm{Cl}^{-}$in the condensate, resulting in the dezincification corrosion happen on the surface of brass. ${ }^{35,36}$ And the production of chloride also increases the sensitivity of dezincification corrosion with the increase of the corrosion time, resulting in the following reaction: $:^{37,38} \mathrm{Cu}^{2+}+\mathrm{Zn} \rightarrow \mathrm{Zn}^{2+}+\mathrm{Cu}$.

Table 6 shows the quality indicators of four fuels. It can be seen that the quality indicators of four fuels is 1a, which indicates the corrosiveness to copper from the four fuels meets the standard.

\subsection{Surface analysis}

The SEM image of the metals corroded in the condensates for $0 \mathrm{~h}$ and $168 \mathrm{~h}$ are shown in Fig. 5. As shown in Fig. 5, before immersion, the metals exhibited a relatively smooth surface, and the polishing scratches is still clearly visible. The surface of the metals after immersion in the different condensates for $168 \mathrm{~h}$ is exhibited the different degrees of corrosion, and the surface of the metals is no longer smooth. The surface of Q245 and corten steel is corroded seriously comparing with other metals, and covered a thicker corrosion product. And it exhibits the occurrence of strongly uniform corrosion in those condensates. ${ }^{39,40}$ With the increase of diesel fuel content in the

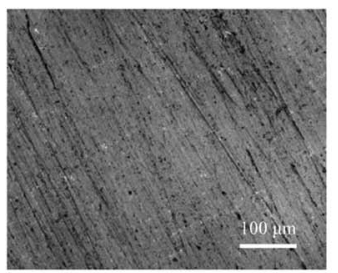

brass-0h-blank

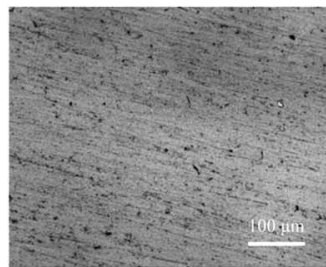

304-0h-blank

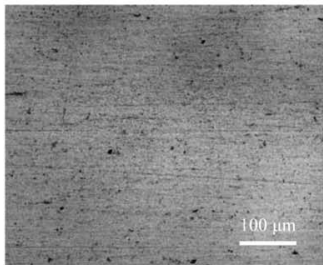

316-0h-blank

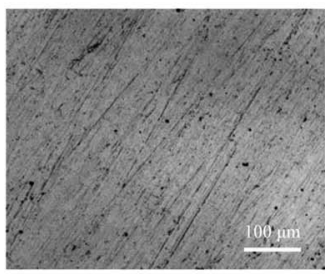

Q245-0h-blank

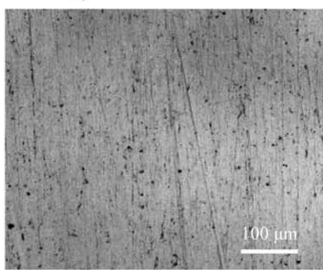

Corten steel-0h-blank

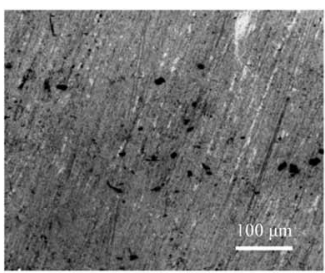

brass-methanol

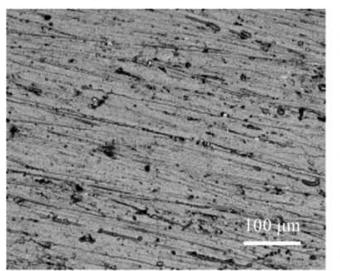

304-methanol

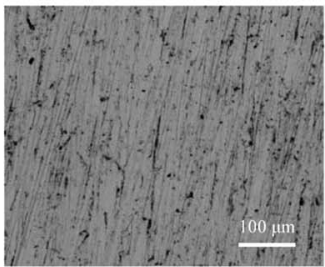

316-methanol

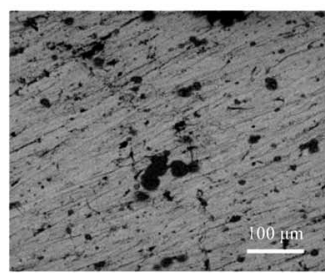

Q245-methanol

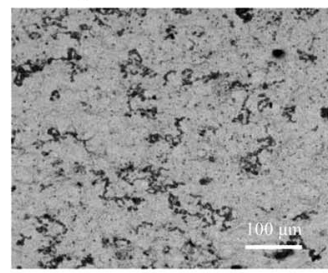

Corten steel-methanol

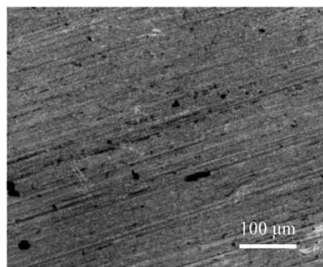

brass-diesel oil

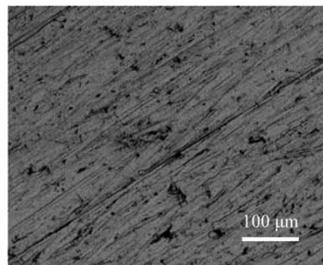

304-diesel oil

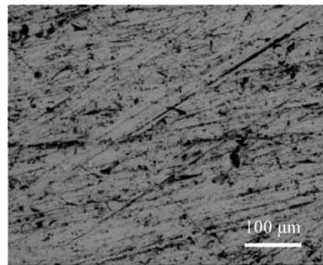

316-diesel oil

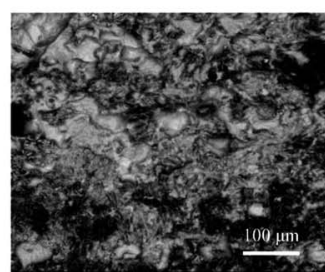

Q245-diesel oil

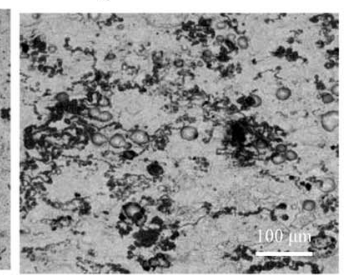

Corten steel-diesel oil

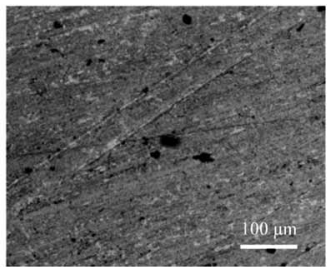

brass-MF75

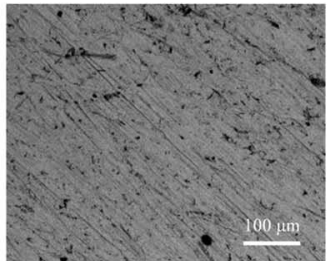

304-MF75

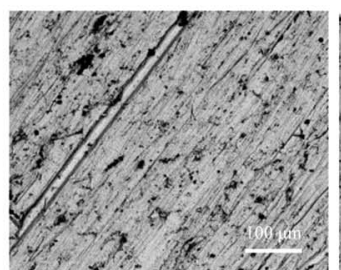

316-MF75

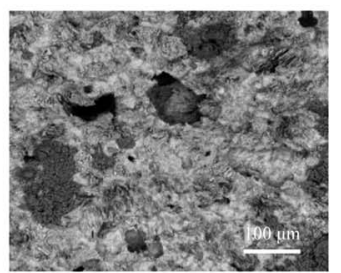

Q245-MF75

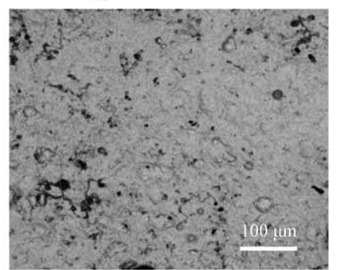

Corten steel-MF75

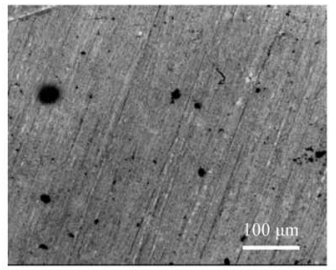

brass-MF50

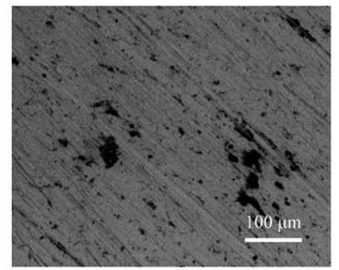

304-MF50

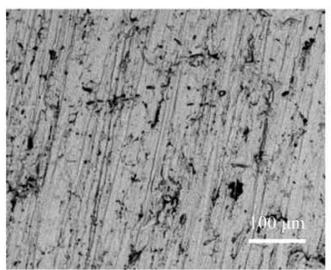

316-MF50

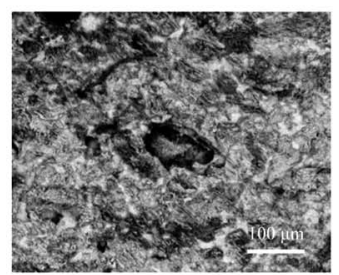

Q245-MF50

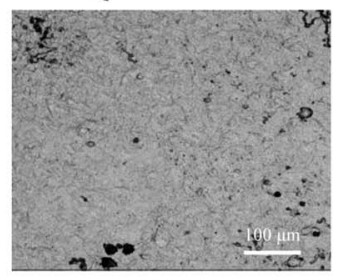

Corten steel-MF50

Fig. 5 The SEM image of the metals corroded in the condensates for $0 \mathrm{~h}$ and $168 \mathrm{~h}$. 
fuel, the corrosion of condensates to metal surface is more serious. The corrosion product of Q245 is relatively loose and that of corten steel is compact relatively, indicating the corrosion product has a certain protective effect on the substrate of corten steel. The concentration of $\mathrm{SO}_{4}{ }^{-}$in condensate of the diesel oil combustion is high relatively, resulting in the Q245 steel corrosion seriously. The surface of brass, 304 and 316 stainless steel occur some pitting, and chloride in acidic corrosive medium is the main cause of pitting. ${ }^{41}$ The joint action of various alloying elements in stainless steel, and the corrosion degree is relatively slight. The oxide film of brass is penetrated easily with $\mathrm{Cl}^{-}$, resulting in the diffusion and increase of pits or damaged areas, and accelerating the corrosion of the brass surface. ${ }^{42}$

\section{Conclusion}

The acid dew point experiment test shows that, compared with diesel oil, the methanol, MF75 and MF50 are more conducive to the recovery and utilization of the tail heat and improve the thermal efficiency in industrial boiler. The lower of acid dew point, the less prone to low temperature corrosion in the lowtemperature area of the boiler, which is more conducive to the safe and energy-saving operation of the boiler.

The analysis of electrochemical and static immersion corrosion test shows that the corrosion resistance properties of stainless steel is better than that of carbon steel to the condensates of the four fuels combustion. The corrosion resistance properties of 316 stainless steel is the best among the five kinds of metal, showing it would be the excellent material choice for the low-temperature area of boiler. The condensate of the methanol is clean, and the corrosion of metals in the condensate of the methanol combustion is relatively weaker than that in the condensate of the diesel combustion. The ratio of the diesel oil increase in the fuel, resulting in the enhancement of the corrosion of condensate. And the quality indicators of four fuels meet the relevant standards for the corrosion of the copper sheet, indicating their corrosion safety.

Surface analysis shows that the main corrosion form of the carbon steel is severe general corrosion, and that of the stainless steel and brass are local pitting. After static immersion in the condensates, the surface roughness of the carbon steel increased rapidly and severe corrosion occurred obviously. The surface corrosion products of Q245 steel are relatively loose, and that of the corten steel are relatively tight. For the lowtemperature area of the boiler, the corten steel is more conducive to the accumulation of corrosion products on the metal surface than the Q245 steel, which causes serious dust accumulation and affects the safe operation of the boiler. Stainless steel can be used in areas where the temperature is low and the corrosion is serious because the corrosion products on the surface are very few.

\section{Conflicts of interest}

There are no conflicts to declare.

\section{References}

1 S. Liang and C. Jiang, J. Chin. Soc. Corros. Prot., 2018, 38, 105116.

2 W. Cai, Chem. Eng. Des. Commun., 2018, 44, 79.

3 X. Guan, Chem. Eng. Des. Commun., 2018, 44, 81.

4 O. I. Awad, R. Mamat, O. M. Ali, et al., Renewable Sustainable Energy Rev., 2018, 82, 2586-2605.

5 A. Jamrozik, W. Tutak, M. Pyrc, et al., Fuel, 2018, 221, 329345.

6 N. H. Kasmuri, S. K. Kamarudin, S. R. S. Abdullah, et al., Renewable Sustainable Energy Rev., 2017, 79, 914-923.

7 X. Z. Fu, T. Q. Guan, Z. H. Xu, et al., Journal of Hunan University of Science and Engineering, 2006, 27, 73-75.

8 A. N. Oumer, M. M. Hasan, A. T. Baheta, et al., Renewable Sustainable Energy Rev., 2018, 88, 82-98.

9 J. Barroso, J. Ballester and A. Pina, Fuel Process. Technol., 2010, 91, 1537-1550.

10 M. S. Jia and C. M. Ling, Industrial Boiler, 2003, 31, 31-35.

11 P. Pan, H. Chen, Z. Liang, et al., Corros. Sci., 2018, 131, 126136.

12 M. C. Barma, R. Saidur, S. M. A. Rahman, et al., Renewable Sustainable Energy Rev., 2017, 79, 970-983.

13 E. Vainio, H. Kinnunen, T. Laurén, et al., Fuel, 2016, 184, 957-965.

14 P. F. Li and H. L. Tong, Boiler Technology, 2009, 40, 5-8.

15 H. P. Nielsen, F. J. Frandsen, K. Dam-Johansen, et al., Prog. Energy Combust. Sci., 2000, 26, 283-298.

16 A. Demirbas, Prog. Energy Combust. Sci., 2005, 31, 171-192.

17 M. Li, S. Tang, F. Wang, et al., Appl. Therm. Eng., 2017, 126, 737-761.

18 Y. Niu, H. Tan and S. Hui, Prog. Energy Combust. Sci., 2016, 52, 1-61.

19 J. Z. Zhang, Total Corrosion Control, 2012, 26, 1-6.

20 B. X. Xiang, W. C. Xing, J. F. Li, et al., Boiler Technology, 2014, 45, $1-4$.

21 Z. A. Shen, H. X. Liu and J. G. Li, China Environmental Protection Industry, 2015, 54-57.

22 J. Li, W. P. Yan, B. T. Gao, et al., Therm. Power Gener., 2009, 40, 14-17.

23 H. Luo, H. Su, B. Li, et al., Appl. Surf. Sci., 2018, 439, 232-239.

24 K. Zheng, H. Y. Li and Y. H. Han, Shandong Chem. Ind., 2014, 43, 129-130.

25 P. X. Lin, Y. W. Jie and G. D. Mo, Chem. Eng. Oil Gas, 2009, 38, 400-401.

26 S. He, Research on Corrosion Resistance Materials and Waste Heat Utilization System for Utility Boiler, North China Electric Power University, 2017.

27 X. Wang, J. Wu, L. Diao, et al., J. Nucl. Radiochem., 2014, 36, 45-49.

28 W. Wang, New Process for Surface Passivation of Stainless Steel Cathode Materials and its Performance and Application, Kunming University of Science and Technology, 2006.

29 J. W. Bond and E. Lieu, Appl. Surf. Sci., 2014, 313, 455-461.

30 T. Meesak and C. Thedsuwan, Mater. Today, 2018, 5, 95609568. 
31 X. F. Zhang, J. Wang, H. Y. Fan, et al., Appl. Surf. Sci., 2018, 440, 755-762.

32 D. X. Shao, M. Wu, F. Xie, et al., J. Liaoning Shihua Univ., 2018, 38, 26-30.

33 X. D. Pan and X. M. Wang, Ind. Water Treat., 2013, 33, 14-16.

34 X. S. Dong, B. C. Wang and L. Y. He, Corros. Sci. Prot. Technol., 2013, 25, 387-392.

35 T. T. Zhou, P. Cao and C. Q. Yuan, , et al., Corros. Prot., 2014, 35, 407-412.

36 Q. J. Feng, Study of Electrochemical Corrosion Behaviors of Copper, Zinc and their Alloy, Huazhong University of Science and Technology, 2015.
37 C. M. Zhao, M. Q. Jia and J. H. Huo, J. Beijing Univ. Chem. Technol., 2000, 27, 62-65.

38 Q. J. Feng, X. P. Xia, H. Zou, et al., Chem. Bioeng., 2015, 32, 14-18.

39 X. H. Li and G. N. Mu, Appl. Surf. Sci., 2005, 252, 1254-1265.

40 G. N. Mu and X. H. Li, J. Colloid Interface Sci., 2005, 289, 184192.

41 Z. H. Jin, H. H. Ge, W. W. Lin, et al., Appl. Surf. Sci., 2014, 322, 47-56.

42 Q. Hong, Y. B. Wang and B. R. Hou, Appl. Chem. Ind., 2005, 34, 31-34. 